\title{
James Pringle.
}

James Pringle was born in Edinburgh in 1822. He was the son of Mr Murray Pringle, who for thirty years held the office of Secretary in the Adjutant-General's Office, and a similar position in the Naval and Military Academy, which long existed in the city. He received his education at the High School of Edinburgh, where he made great proficiency in the study of the classics, and stood third among his fellow-students in the list of honours during the last year of his educational course.

On leaving the High School he became a clerk to the Edinburgh Roperie Company. His business abilities and capacity for hard work led to his being promoted to the position of cashier in the Company's office, and on the occurrence of a vacancy in the management the entire responsibility of conducting the Company's business was devolved on him.

About six years ago, he began to take a prominent part in the public business of Leith, when he was returned as representative of the ratepayers to the Leith Dock Commission. Entering the Town Council of Leith in 1881, he was elected Provost of the burgh in November of that year, and continued to occupy the position till the time of his death. Like his predecessor in the civic chair, he was an ardent supporter of the Leith improvement scheme, and he was particularly active in obtaining a Provisional Order for the better preservation of Leith Links. He displayed great tact and energy, as well as infailing courtesy, in the discharge of his onerous duties as chief Magistrate, and he took an active interest in all associations and movements for the amelioration of the condition of the poor, and the relief of suffering.

Mr Pringle also held the honourable office of Deputy-Lieutenant of the county. $\mathrm{He}$ found time to take an intelligent interest in the proceedings of the Geographical Society, and he was elected a Fellow of this Society on the 6th of April 1885. He died on the 11th of December 1886. His funeral, which was a public one, called forth an expression of general sympathy and regard, such as, perhaps, had never before been witnessed in the town over which he presided. 